\title{
Aerial Root Structure and Its Significance for Function in Dracaena draco
}

\author{
Joanna Jura-Morawiec ${ }^{1} \cdot$ Pedro Monroy $^{2} \cdot$ Aguedo Marrero $^{2} \cdot$ Mirela Tulik $^{3}$
}

Received: 26 June 2019 / Accepted: 8 May 2020 / Published online: 25 May 2020

(c) The Author(s) 2020

\begin{abstract}
The dragon tree, Dracaena draco, is a vulnerable species. In response to stress it forms aerial roots (AR). Although the exact function of these AR is unknown, it has been the subject of speculation on the basis of morphological observations. This study aims to investigate the structural organization of the $D$. draco AR compared to the background of the structure of its soil roots. The material was obtained from the collection of dragon trees growing at Jardín Botánico Canario "Viera y Clavijo" on Gran Canaria as well as from the plants obtained from the commercial nursery. Based on hand-cut sections and permanent preparations, we analysed (a) AR structure along its length encompassing the active and dormant state of the AR tip, as well as (b) the general structural organization of the soil roots (stem-borne, lateral and fine roots). We observed that AR are similar to the lateral soil roots in terms of the distribution of the primary and secondary tissues. AR are protected by rhizodermis and/or hypodermis which undergoes metacutization during the transition from the active to dormant state of the AR tip. Chloroplasts are present in cortical parenchyma cells along the entire length of the AR. The obtained anatomical findings are discussed in the context of the putative AR functions.
\end{abstract}

Keywords Anatomy $\cdot$ Arborescent monocots $\cdot$ Primary growth $\cdot$ Secondary growth $\cdot$ Stress

\section{Introduction}

Dracaena draco (Asparagaceae), a monocotyledonous dragon tree, is a vulnerable species (IUCN 2019) with very rare wild populations limited to the Canaries, Morocco, Cape Verde and Madeira (Marrero et al. 1998; Marrero and Almeida-Perez 2012). Studies regarding the structure of this plant date back the turn of the 19th and twentieth centuries (Scott and Brebner 1893; Cheadle 1937; Tomlinson and Zimmermann 1969) and have recently attracted the attention of scientists once again. New information has

Joanna Jura-Morawiec

j.jura@gazeta.pl

1 Polish Academy of Sciences Botanical Garden-Centre for Biological Diversity Conservation in Powsin, Prawdziwka 2, 02-973 Warsaw, Poland

2 Jardín Botánico Canario "Viera y Clavijo" - Unidad Asociada CSIC, Cabildo de Gran Canaria, Camino al palmeral 15, 35017 Las Palmas de Gran Canaria, Spain

3 Department of Forest Botany, Warsaw University of Life Sciences - WULS, Nowoursynowska 159, 02-776 Warsaw, Poland been gathered on the micromorphology and anatomy of its leaves (Klimko and Wiland-Szymańska 2008; Nadezhdina et al. 2015; Klimko et al 2018), leaf contribution to water collection (Nadezhdina and Nadezhdin 2017), intricacies of the stem vascular system (Carlquist 2012; Jura-Morawiec and Wiland-Szymańska 2014; Jura-Morawiec 2015, 2017) and secretion of a red resin named dragon's blood (JuraMorawiec and Tulik 2015, 2016). Despite the progressive research, our current knowledge in the anatomy and physiology of D. draco (and other monocot tree species) is still very limited compared to dicot woody species. Deeper understanding of the specific physiological mechanisms exploited by $D$. draco is necessary for developing a rescue plan ensuring continuous existence of this species.

Exposure of $D$. draco to stress conditions can cause the formation of aerial roots (AR) that typically emerge from the stem and/or branches (Byström 1960; Krawczyszyn and Krawczyszyn 2014). As a result, the shape of this monocot tree changes considerably (Fig. 1). Despite the striking appearance of these structures, physiological functions and significance of AR for D. draco vigour are completely unclear. Water deficiency in the soil (Lyons 1974) as well as wounding of stem or branches (Krawczyszyn 
Fig. 1 D. draco AR at Jardín Botánico Canario "Viera y Clavijo" on Gran Canaria. a Characteristic clusters of AR within the crown marked with arrows. b Possible modification in shape of the plant stem associated with AR appearance, it is shorter and thinner towards the apex. c $D$. draco subsp. caboverdeana with the huge number of AR formed by the branches, stem and underground root system (arrow)
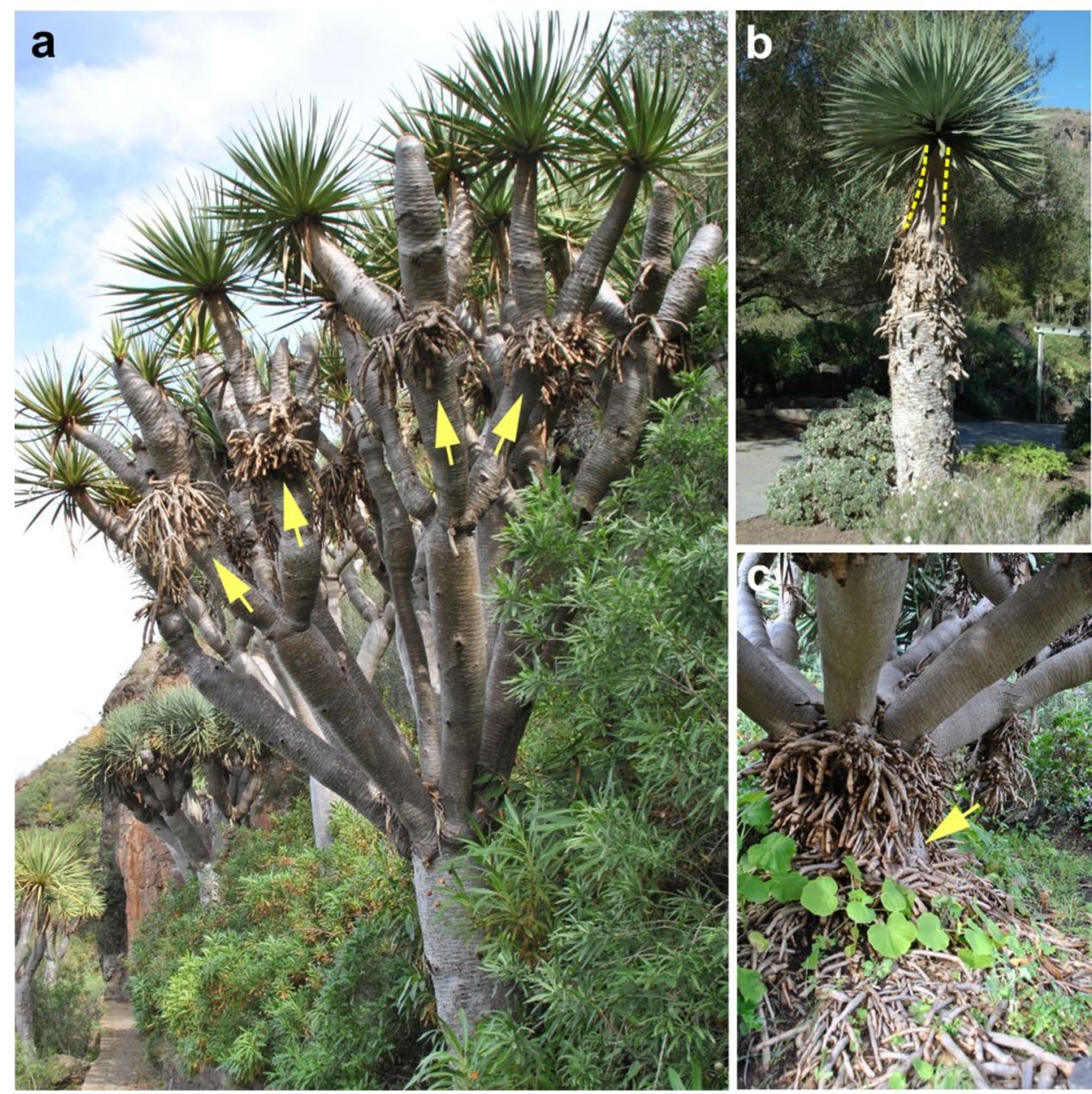

and Krawczyszyn 2014) seem to promote their formation. Assumptions about the role of AR in $D$. draco are based mainly on morphological observations that allowed to distinguish two major types of AR. Massive AR are considered to play a mechanical role by adding to the girth of the stem (Krawczyszyn and Krawczyszyn 2014). In contrast, small and thin AR are associated with certain modifications of the plant body, such as fewer and shorter leaves or shorter branches, and these are considered to be involved in the absorption of moisture from the atmosphere (Lyons 1974). In agreement, seasonal observations of AR development in $D$. draco revealed that these organs undergo periodic elongation with the maximum extension growth during the months with the greatest rainfall totals (Jura-Morawiec 2019).

The structure of AR of $D$. draco remains poorly described which precludes deciphering their functional roles. Apart from the recent statements by Krawczyszyn and Krawczyszyn (2014) that these AR contain chloroplasts behind the thick layer of cork and possess secondary tissue similar in structure to those of the stem, there is no information in this field. We aimed to investigate the structural organization of AR, during their active and dormant state, relative to the structural organization of the soil roots in $D$. draco. Also, we discuss the anatomical findings in the context of AR putative functions.

\section{Materials and Methods}

\section{Plant Material and Sampling}

The AR samples were obtained from the collection of $D$. draco growing at Jardín Botánico Canario "Viera y Clavijo" on Gran Canaria where dragon trees grow in their natural vegetation belt (the thermo-sclerophyllous forest). The material was collected during four stays on Gran Canaria (XI 2017, I/II, V, VIII 2018), i.e. during the dry and wet seasons. The AR were obtained from the crowns, stem and from the surface of the ground. In each case, the AR were of the 1st or 2 nd order (with a mean diameter of $1-2.5 \mathrm{~cm}$ in the region of insertion to the branch, stem or root), and all were positively gravitropic. Comparative anatomical studies were carried out with the underground root system of two $D$. draco plants (unbranched stem; $1.3 \mathrm{~m}$ in height) obtained from the 
commercial nursery. Based on the position and morphology, the following soil root categories were distinguished: (i) stem-borne, thick ( $3.5-5 \mathrm{~cm}$ in diameter), adventitious roots with above and below ground root parts, (ii) their laterals (lateral roots) $\sim 2-2.5 \mathrm{~cm}$ in diameter, and (iii) a net of fine roots.

\section{Sample Preparation and Microscopy}

The AR were sectioned transversely by hand into successive pieces at known distances from the root tip, in order to track changes in the root structure during maturation. To analyse the anatomical structure of the AR and soil roots, we produced hand-cut sections and permanent preparations. Some of the samples were subdivided into smaller blocks, fixed in FAA and embedded in Epon resin, as described by Meek (1976). The embedded material was cut transversely with a Leica 480A ultramicrotome into sections $3.5 \mu \mathrm{m}$ thick and attached to slides with Haupt's adhesive. Next, slides with attached sections were stained with PAS (Periodic Acid Schiff) and toluidine blue for general histology and mounted in Euparal (Roth, Germany). Other thin sections were treated with a $0.02 \%(\mathrm{w} / \mathrm{v})$ aqueous solution of ruthenium red for pectins. Large samples (ca. $1.5 \mathrm{~cm} \times 2.5 \mathrm{~cm} \times 3 \mathrm{~cm}$ ) were cut transversely and longitudinally with a core microtome (WSL, Birmensdorf, Switzerland) stained with safranin O, dehydrated with ethanol series (50-100\%) and mounted in Euparal.

The sections stained with PAS and safranin O were examined under transmitted light using an Olympus BX41 microscope equipped with a Canon EOS 70D camera. The unstained, thin sections were examined under UV light with LED fluorescent microscope Zeiss Axio.Lab1. Some of the samples fixed in FAA and stored in ethanol were examined using the FEI Quanta 200 ESEM scanning electron microscope with the EDS EDAX analyzer. Observations and photos were taken in low vacuum mode (up to $1 \mathrm{Tr}$ ). The proportion of secondary tissue was calculated as a ratio of cross-sectional area occupied by a cylinder containing amphivasal vascular bundles to area of the whole AR crosssection, based on the measurements made with OptaView 7 (Opta-Tech, Poland).

\section{Results}

The D. draco AR formed long-lived clusters overhanging from the branches and stems or grew from the underground root system and then appeared on the surface of the ground (Fig. 1). Irrespective their location within plant body, AR showed a similar general tissue pattern and organization i.e. the rhizodermis, beneath which occurred the cortex (comprising hypodermis, cortical parenchyma and endodermis) enclosing the stele. The stele consisted of a pericycle, xylem and phloem with an exarch arrangement and a parenchymatous pith (Fig. 2a-d).

We examined the anatomy of AR in the direction from the tip towards the base to assess anatomical changes during their ontogenetic development. Apart from the tip, which is protected by a root cap, the surface of the outermost tissue of the AR contained numerous cracks (Fig. 2b, h). When the AR was active, near the tip, a thin-walled rhizodermis (lacking root hairs) was observed (Fig. 2e). However, during elongation, the rhizodermis gradually peeled away, so that the underlying hypodermis became exposed and eventually became the outermost tissue (Fig. 2f). Additionally, AR tip was coated with mucilage-like covering (not shown). With increasing distance from the AR tip (and when AR entered the dormant state) the process of metacutization proceeded on the hypodermal cell layers. The hypodermis walls had a patchy appearance when viewed in thin sections under autofluorescence following UV excitation (Fig. 2g). In ontogenetically older regions of AR, the sub-hypodermal layers of cortical parenchyma became crushed, and individual periclinal (tangential) cell divisions were observed (Fig. 2i). Beneath the hypodermis, cortical parenchyma cells containing chloroplasts were present along the entire length of the AR (Fig. 2j, k). The endodermis, the innermost layer of the cortex, was characterized by three consecutive developmental states along the AR length: state I-deposited Casparian bands; state II-deposited suberin lamellae and state III-endodermal cells with thick, lignified, u-shaped walls. However, the distance between the AR tip and initiation points of states I-III varied considerably in investigated AR indicating an asynchronous development of endodermis in this organ (Fig. 21). While endodermal cells in states I-II typically occurred close to the AR tip, endodermis in state III was typically developed at the distances of $\sim 3.5 \mathrm{~cm}$ and greater from AR tip (i.e. in region produced during previous year; Fig. $2 \mathrm{~m}$ ). Within the stele, AR laterals originated from the cells of the pericycle (Fig. 2n) to form characteristic clusters (Fig. 1). In general, the primary vascular tissues were located far from the center of the organ and formed a cylinder around the wide pith, which was traversed by sclerenchymatous strands enclosing either vessels or sieve tubes (Fig. 2c-d, n). Secondary vascular tissues were arranged in amphivasal bundles embedded in the ground tissue (Fig. 2o). The investigated AR had relatively thin cylinder of secondary growth (18\% of the total AR volume) at the base of the AR as well as near the insertion of the lateral root (Fig. 2n-o). The distance from the AR tip to secondary growth initiation varied considerably.

For comparison, we studied the structural configuration of the three different categories of soil roots of $D$. draco i.e. stem-borne, lateral and fine roots (Fig. 3a). There were substantial differences in occurrence and proportions of various 


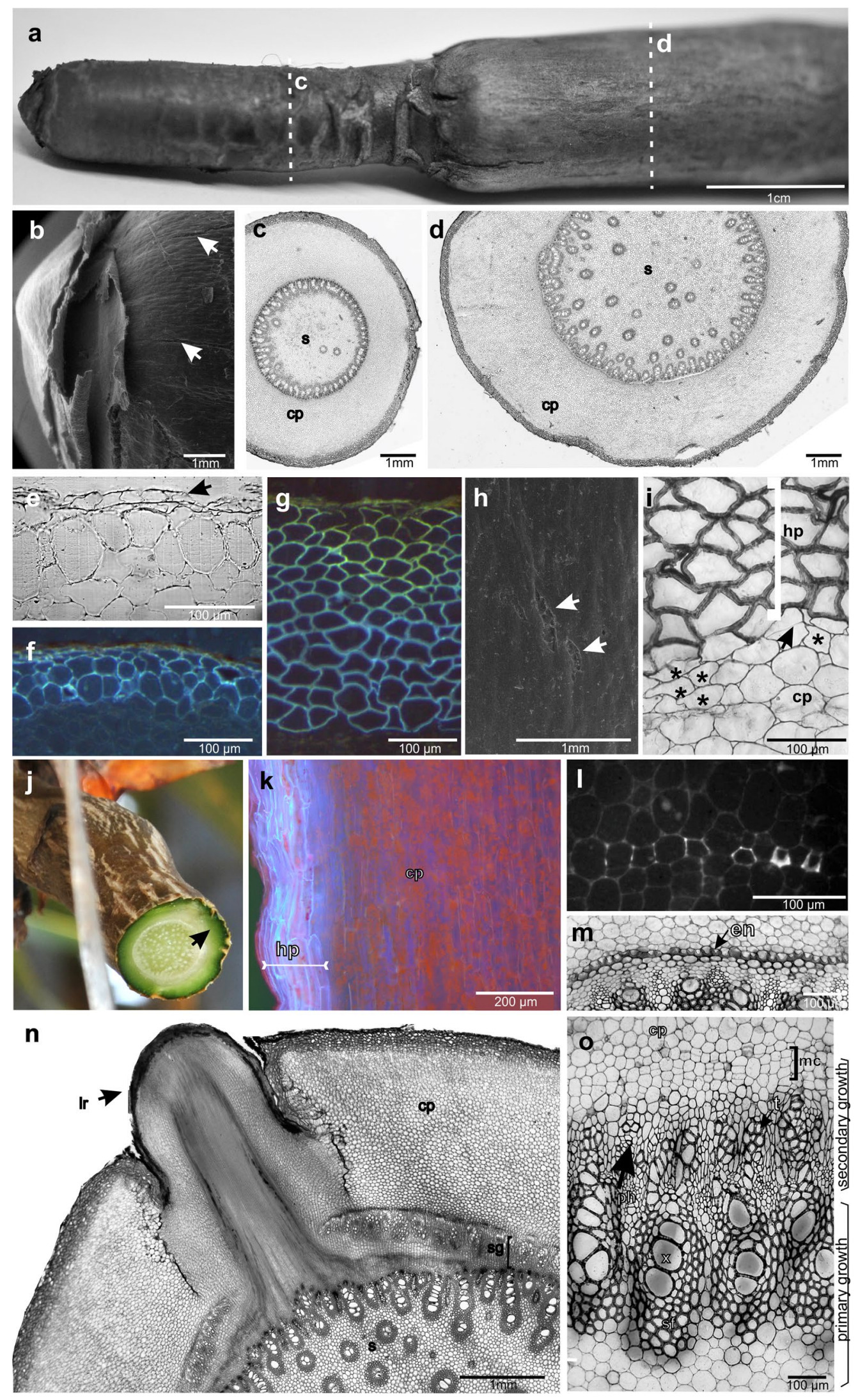


4Fig. 2 Structural details of the AR in the active and dormant state. a General view of the representative AR with visible thinner, new part produced during the current year and thicker, older part formed in a previous season; positions of the sections $\mathrm{c}-\mathrm{d}$ were marked with dashed lines. b SEM view of an active tip, note the cracks (marked with arrows) on its surface. c-d Transverse sections of the newly formed AR part and that formed in a previous year. e-g Transverse sections showing successive stages in the development of protective tissues; position of rhizodermis on e is marked with an arrow, hypodermis along the AR as viewed using UV light is shown in $\mathrm{f}-\mathrm{g}$, with patchy appearance of cell walls on $\mathrm{g}$. $\mathbf{h}$ SEM view of the AR surface with cracks marked with arrows. i Transverse, thin section showing the boundary between hypodermis and cortical parenchyma in the AR part with monocot cambium activity. Note the thickness of the cell walls of the hypodermis, the deformed cells of cortical parenchyma (asterisks), and a periclinal cell division (arrow). j View of a sectioned AR showing characteristic cracks on its surface, and a green cortex (arrow) indicating the presence of chloroplasts. $\mathbf{k}$ Radial section of the outermost cortex (UV light) with visible chloroplasts. Transverse, thin sections showing $\mathbf{I}$ asynchronous development of endodermis (UV light), $\mathbf{m}$ endodermis in state III composed of cells with thick, lignified, u-shaped walls, $\mathbf{n}$ emerging lateral root, and $\mathbf{o}$ parts of stele region with visible secondary growth. $c p$ cortical parenchyma, en endodermis, $h p$ hypodermis, $l r$ lateral root, $m c$ monocot cambium, $p h$ phloem, $s$ stele, $s f$ sclerenchyma fibres, $s g$ secondary growth, $t$ tracheids, $x$ xylem vessels

types of protective (rhizodermis, hypodermis, storied cork) as well as secondary vascular tissue (i.e. a cylinder formed by monocot cambium containing amphivasal vascular bundles embedded in the ground tissue) across the examined root categories (Fig. 3f). The stem-borne roots were covered with layers of cells (storied cork) formed during periclinal divisions of cortex cells. The majority of the stem-borne root cross-section (69\%) comprised of secondary vascular system enclosing small stele (Fig. 3b, f). Lateral roots were protected by a multilayered hypodermis and/or storied cork. The secondary vascular cylinder contained $16 \%$ of the root cross-section. In the fine roots, the stele was relatively small (Fig. 3d-f). The thinnest, fine roots contained the rhizodermis with root hairs, while the thicker ones $(>2 \mathrm{~mm})$ were covered with multilayered hypodermis replaced gradually by storied cork (Fig. 3d-e). Parts of the stem-borne and lateral roots situated above/on the ground possessed chloroplasts within the cortex.

\section{Discussion}

\section{AR vs. Soil Root Structure}

In general, D. draco $\mathrm{AR}$ and soil roots have similar structure, although some differences relate to the contribution of secondary growth and protective tissue. Secondary growth of roots is a unique feature among monocotyledons, characteristic only for Dracaena spp. (Scott and Brebner 1893; Cheadle 1937; Carlquist 2012). Results of this and other studies demonstrated that the pattern of secondary growth in soil roots is similar to that in the stem (Tomlinson and Zimmermann 1969) and AR (Krawczyszyn and Krawczyszyn 2014). In all organs, amphivasal vascular bundles embedded in the ground tissue are formed during monocot cambium activity. Maximum contribution of secondary tissues is characteristic for the stem-borne roots (69\%) which are responsible for supporting and anchoring the plant. In AR (of the first order), the contribution of secondary growth is similar to those of lateral soil roots (Figs. 2c-d, 3f).

The protective tissue of AR is relatively thin and in the older parts of this organ is about twice thinner than in the lateral soil roots. Thickening of the AR entails the individual periclinal (tangential) cell divisions in the sub-hypodermal layers of cortical parenchyma and the formation of protective tissue similar to that of the stem (storied cork, JuraMorawiec et al. 2015).

\section{AR Structure in Relation to Function}

Based on the studies of different types of aerial roots, both monocotyledonous and dicotyledonous species, it can be concluded that the principal physiological function of the aerial root system is similar to that of the primary root system-to extract water and nutrients from the surroundings (Barlow 1986). Lyons (1974) suggested that D. draco AR might be involved in the absorption of moisture from the atmosphere. Our studies demonstrated that AR do not possess special tissue like velamen. Nonetheless, the thickness and composition of protective tissue in the apical AR part depend on the phase of growth, as AR grow periodically (Jura-Morawiec 2019). AR water absorption could be possible during their active phase of growth, i.e. when rains occur. Then, the multilayered, lignified and cracked hypodermis with a superficial pectin layer protects the apical AR part. In contrast, during the dormant phase, metacutization proceeds and protects the AR from desiccation, thus possibly hindering water absorption. However, it can be expected that certain radial water transport is still possible through this modified (suberized) layers of cells (Kim et al. 2018). Considering the fact that AR significantly increase the total surface area of the aboveground organs, the contribution of AR in a dormant state to the overall plant water uptake may be significant, especially as dragon trees grow in areas with seasonally dry climate subject to fog occurrence (Marzol et al. 2011), that can be an additional water source.

The aboveground growth of AR is associated with exposure to light and the presence of chloroplasts. The AR of orchids, pneumatophores of mangroves and the stilt roots of some palms are believed to possess the ability to photosynthesize (Goh et al. 1983; Dromgoole 1988; Aschan and Pfanz 2003) and contribute to the carbon economy of the whole plant. The appearance of parenchyma cells bearing 
Fig. 3 Structural detail of D. draco soil roots. a Distinguished root categories, letters refer to the following transverse sections b-e. b Stem-borne, thick, anchoring root. $\mathbf{c}$ Lateral, shallow root going horizontally. d Fine root with a multilayered hypodermis and storied cork beneath. Note dimensional relationship between $\mathrm{b}-\mathrm{d}$ as these sections are at the same scale. $\mathbf{e}$ Fine, absorbing root; a part of a section across the root hair zone (UV) with visible the rhizodermis and exodermis. f Simplified scheme of the distribution of the primary and secondary vascular tissues in the distinguished root categories. $c p$ cortical parenchyma, $h$ hypodermis, $r h$ rhizodermis, $s$ stele, $s c$ storied cork, $s g$ secondary growth
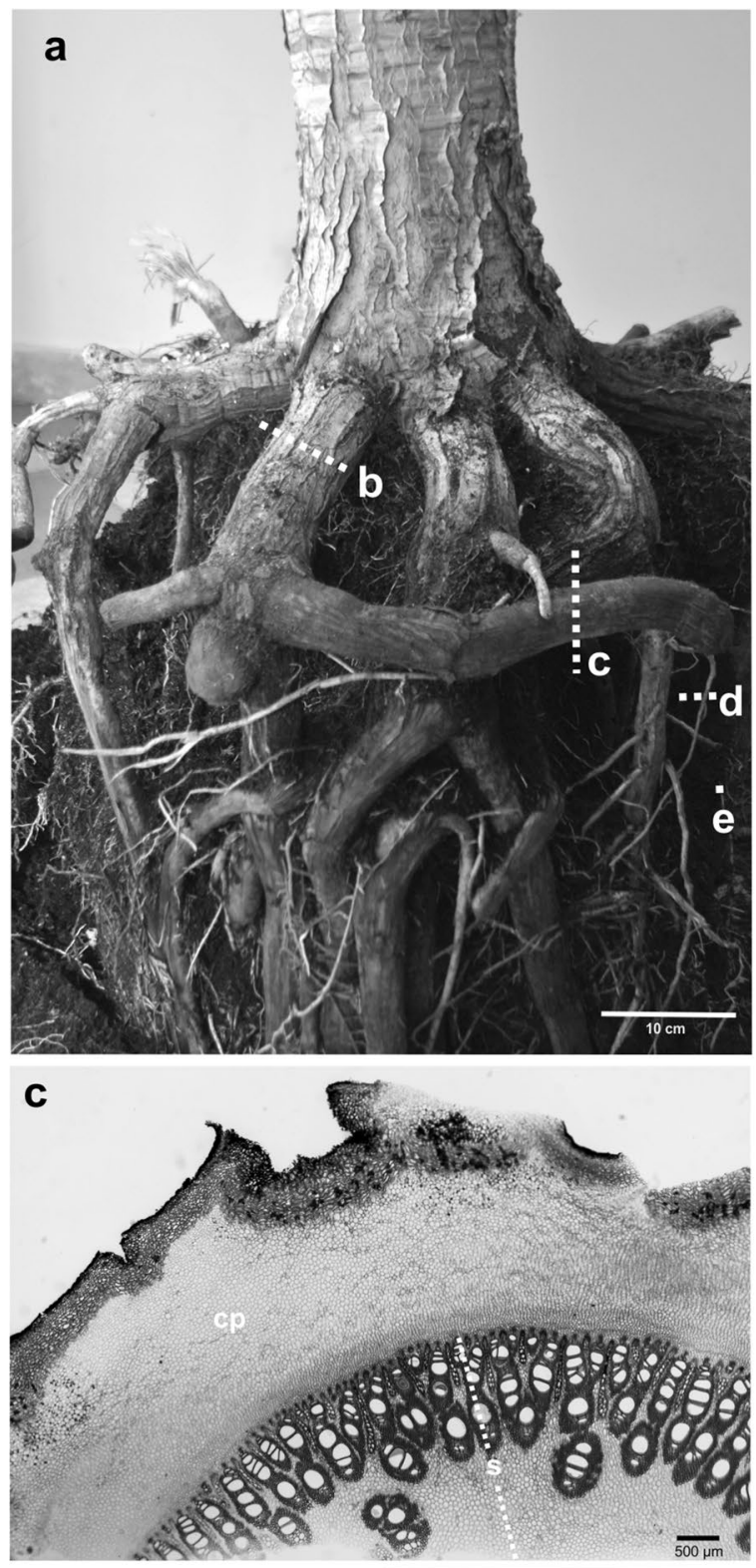

\section{b}

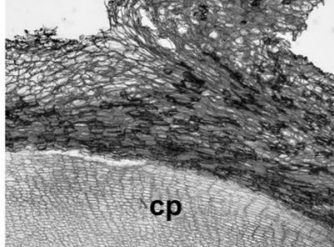

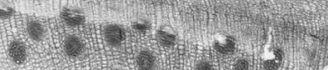
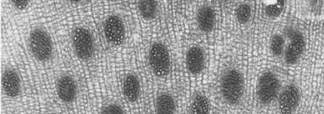

.

e

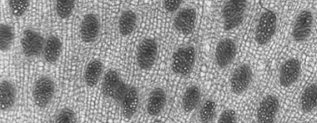

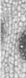
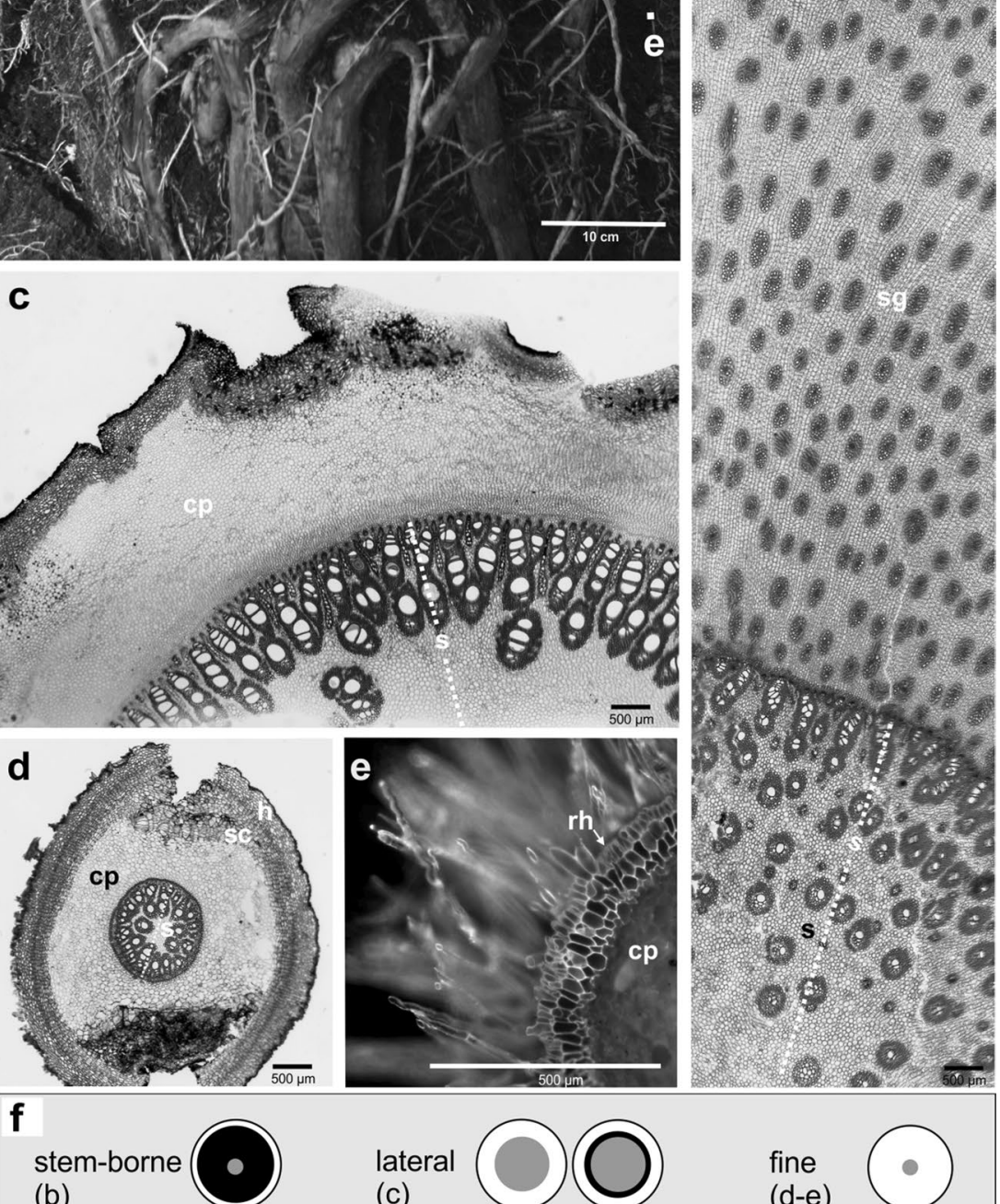

lateral

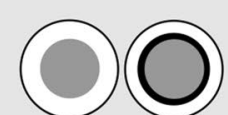

fine

(d-e)

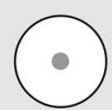

Key: stele $\bigcirc$ cortex secondary growth 
chloroplasts within $D$. draco AR, together with their lack of similarities to leaf tissue-absence of stomata or palisade layer (Pfanz and Aschan 2001), indicates the occurrence of corticular photosynthesis and a capability to assimilate respiratory carbon. The protective tissue of these organs usually masks the presence of chloroplasts, which are, however, noticeable along the entire length of the AR, even in the region of secondary growth. Pfanz et al. (2002) pointed out that corticular photosynthesis is reduced during plant organ ageing mainly due to the development of thicker outer bark layers. In such a situation, a tree has to provide a sufficient area of new parts to maintain a carbon budget. Krawczyszyn and Krawczyszyn (2014) described cases where clusters of AR cling tightly to the $D$. draco trunk and grow downwards, suggesting that such bonding revitalizes the tree and helps trunk to thicken considerably. It seems reasonable to assume that $D$. draco AR also contribute to rejuvenating the stem/ branch photosynthetic abilities/tissues.

According to Jupa et al. (2017), soluble, non-structural carbohydrates are the major representatives of the carbohydrates in D. marginata and their concentration is significantly higher in the roots compared to the stem. The authors investigated this species at its primary state of growth and concluded that parenchyma-rich roots and stem together with an accumulation of osmotic compounds help the plant avoid excessive water loss, tolerate limited long-term water availability and restore their reserves after watering. The accumulation of the osmotically active substances described above is a common mechanism activated by plants under conditions of water stress (Martinez et al. 2004; Zlatev and Lidon 2012). Taking into account that $D$. draco AR are mainly composed of the parenchymatous thin-walled cells, the AR can be considered as an additional storage compartments of the dragon tree capable of storing water and releasing it to the stem or soil roots, although further studies are needed to clarify this issue.

To conclude, our results highlight structural changes along the $D$. draco AR against the background of the structural composition of its soil root system. In general, the AR are anatomically similar in terms of the distribution of the primary and secondary tissues to the lateral soil roots. The AR structure favours their principal function of increasing plant water absorption and storage surface in stress conditions. We hope that results of this study will help to streamline further research aiming at elucidation of physiological functions of AR of D. draco and their significance for the survival of this species.

Acknowledgements We thank Dr. J. Caujapé-Castells, director of the Jardín Botánico Canario "Viera y Clavijo"-Unidad Asociada al CSIC of the Cabildo de Gran Canaria, for facilitating collection of AR samples from dragon trees. We also thank an anonymous reviewer for his constructive comments which helped us improve our manuscript. This study was supported in part by the National Science Centre, Poland; Grant Number 2017/01/X/NZ8/00533 (J. J-M).

Author Contributions JJ-M: Study conception and design, collection and preparation of the material, acquisition, analysis and interpretation of data and writing of the manuscript. PM: Collection of the material and reading and comments on the manuscript. AM: data analysis, reading and comments on the manuscript. MT: Preparation of the material, analysis and interpretation of data, writing of the manuscript.

\section{Compliance with Ethical Standards}

Conflict of interest The authors declare that there is no conflict of interest.

Open Access This article is licensed under a Creative Commons Attribution 4.0 International License, which permits use, sharing, adaptation, distribution and reproduction in any medium or format, as long as you give appropriate credit to the original author(s) and the source, provide a link to the Creative Commons licence, and indicate if changes were made. The images or other third party material in this article are included in the article's Creative Commons licence, unless indicated otherwise in a credit line to the material. If material is not included in the article's Creative Commons licence and your intended use is not permitted by statutory regulation or exceeds the permitted use, you will need to obtain permission directly from the copyright holder. To view a copy of this licence, visit http://creativecommons.org/licenses/by/4.0/.

\section{References}

Aschan G, Pfanz H (2003) Non-foliar photosynthesis-a strategy of additional carbon acquisition. Flora 198:81-97

Barlow P (1986) Adventitious roots of whole plants: their forms, functions, and evolution. In: Jackson MB (ed) New root formation in plants and cuttings. Martinus Nijhoff Publishers, Dordrecht, pp $67-110$

Byström K (1960) Dracaena draco L. in the Cape Verde Islands. Acta Hortic Gotob 23:179-214

Carlquist S (2012) Monocot xylem revisited: new information, new paradigms. Bot Rev 78:87-153

Cheadle VI (1937) Secondary growth by means of a thickening ring in certain monocotyledons. Bot Gaz 98:535-555

Dromgoole FI (1988) Carbon dioxide fixation in aerial roots of New Zealand mangrove Avicennia marina var. resinifera (Note). N Z J Mar Fresh Res 22:617-619

Goh CJ, Arditti J, Avadhani PN (1983) Carbon fixation in Orchid aerial roots. New Phytol 95:367-374

IUCN (2019) The IUCN Red List of Threatened Species. https://www. iucnredlist.org. Version 2019-1.https://www.iucnredlist.org. Accessed 21 Mar 2019

Jupa R, Plichta R, Paschova Z, Nadezhdina N, Gebauer R (2017) Mechanism underlying the long-term survival of the monocot Dracaena marginata under drought conditions. Tree Physiol 37:1182-1197

Jura-Morawiec J (2015) Formation of amphivasal vascular bundles in Dracaena draco stem in relation to rate of cambial activity. Trees 29:1493-1499

Jura-Morawiec J (2017) Atypical origin structure and arrangement of secondary tracheary elements in the stem of the monocotyledonous dragon tree, Dracaena draco. Planta 245:93-99 
Jura-Morawiec J (2019) Rhythmic growth and age estimation of aerial roots in Dracaena draco (Asparagaceae). Trees. https://doi. org/10.1007/s00468-019-01880-z

Jura-Morawiec J, Tulik M (2015) Morpho-anatomical basis of dragon's blood secretion in Dracaena draco stem. Flora 2013:1-5

Jura-Morawiec J, Tulik M (2016) Dragon's blood secretion and its ecological significance. Chemoecology 26:101-105

Jura-Morawiec J, Wiland-Szymańska J (2014) A novel insight into the structure of amphivasal secondary bundles on the example of Dracaena draco L. stem. Trees 28:871-877

Jura-Morawiec J, Tulik M, Iqbal M (2015) Lateral meristems responsible for secondary growth of the monocotyledons: a survey of the state of the art. Bot Rev 81:150-161

Kim YX, Ranathunge K, Lee S, Lee D, Sung J (2018) Composite transport model and water and solute transport across plant roots: an update. Front Plant Sci 9:193

Krawczyszyn J, Krawczyszyn T (2014) Massive aerial roots affect growth and form of Dracaena draco. Trees 28:757-768

Klimko M, Wiland-Szymańska J (2008) Scanning electron microscopic studies of leaf surface in taxa of genus Dracaena L. (Dracaenaceae). Bot Steciana 12:117-127

Klimko M, Nowińska R, Wilkin P, Wiland-Szymańska J (2018) Comparative leaf micromorphology and anatomy of the dragon tree group of Dracaena (Aparagaceae) and their taxonomic implications. Plant Syst Evol 304:1041-1055

Lyons $\mathrm{G}$ (1974) In search of dragons or: the plant that roared. Cactus Succul J 46:267-282

Marrero A, Almeida RS, Gonzalez-Martin M (1998) A new species of the wild dragon tree, Dracaena (Dracaenaceae) from Gran Canaria and its taxonomic and biogeographic implications. Bot J Linn Soc 128:291-314

Marrero A, Almeida-Perez R (2012) A new subspecies Dracaena draco (L.)L. subsp. caboverdeana Marrero Rodr. \& R. Almeida (Dracaenaceae) from Cape Verde Islands. Int J Geobot Res 2:35-40

Martinez JP, Lutts S, Schanck A, Bajji M, Kinet JM (2004) Is osmotic adjustment required for water stress resistance in the
Mediterranean shrub Atriplex halimus L.? J Plant Physiol 161:1041-1051

Marzol MV, Sanchez Megia JL, Yanes A (2011) Meteorological patterns and fog water collection in Morocco and the Canary Islands. Erdkunde 65:291-303

Meek GA (1976) Practical electron microscopy for biologists. Wiley, London

Nadezhdina N, Nadezhdin V (2017) Are Dracaena nebulophytes are able to drink atmospheric water? Environ Exp Bot 139:57-66

Nadezhdina N, Plichta R, Nadezhdin V, Gebauer R, Jupa R, Habrova $\mathrm{H}$, Madera $\mathrm{P}$ (2015) A comparative structural and functional study of leaf traits and sap flow in Dracaena cinnabari and Dracaena draco seedlings. Funct Plant Biol 42:1092-1105

Pfanz H, Aschan G (2001) The existence of bark and stem photosynthesis in woody plants and its significance for the overall carbon gain. An eco-physiological and ecological approach. In: Progress in botany, vol 62. Springer, Berlin, pp 477-510

Pfanz H, Aschan G, Langenfeld-Heyser R, Wittmann C, Loose M (2002) Ecology and ecophysiology of tree stems: corticular and wood photosynthesis. Naturwissenschaften 89:147-162

Scott DH, Brebner G (1893) On the secondary tissues in certain monocotyledons. Ann Bot 7:22-62

Tomlinson PB, Zimmermann MH (1969) Vascular anatomy of monocotyledons with secondary growth-an introduction. J Arnold Arbor 50:159-179

Zlatev Z, Lidon FC (2012) An overview on drought induced changes in plant growth, water relations and photosynthesis. Emir J Food Agric 24:57-72

Publisher's Note Springer Nature remains neutral with regard to jurisdictional claims in published maps and institutional affiliations. 